
\title{
B Reserach S Surare \\ Frequency of use of terminal points as an important risk factor for Legionella colonization in hospitals
}

Rafael Manuel Orti Lucas ( $\Delta$ ortilucas@gmail.com )

Universidad Catolica de Valencia San Vicente Martir https://orcid.org/0000-0003-2211-7413

\section{Eugenio Luciano}

Universidad Catolica de Valencia San Vicente Martir

\section{Research article}

Keywords: Legionella, Legionnaires' disease, water distribution systems, colonization, rapid techniques, risk factors, pipe length, chlorine, temperature, terminal points

Posted Date: October 8th, 2019

DOI: https://doi.org/10.21203/rs.2.15735/v1

License: (1) This work is licensed under a Creative Commons Attribution 4.0 International License. Read Full License 


\section{Abstract}

Background: Hospitals have a different structure than domestic buildings. Legionella is a bacterium that can colonize the hospital water causing many outbreaks. It's a Public Health problem and its prevention and control are essential to avoid nosocomial infections. The aims of this study are to evaluate several risk factors and parameters that can contribute to Legionella colonization in a hospital, thereby improving Legionella risk assessment process. Methods

A total of 136 water samples (hot water and cold water) was investigated from different points of a hospital water network. These samples were tested for Legionella sp by three laboratories using different diagnostic tests: culture, polymerase chain reaction (PCR) and a method based on immunomagnetic separation (IMS). The results for these three techniques were combined and interpreted by three microbiologists with the aim of defining a new standard index. A multivariate analysis was performed by logistic regression to estimate the adjusted risk associated with the type of water, length of the pipe, chlorine, temperature, type of terminal point, period of the year, type of health care (ambulatory or hospital) and the frequency of use of the terminal point.

Results: There was no statistically significant difference, on the basis of the new standard index, neither between laboratories nor between diagnostic tests. Positive results of this index were significantly correlated with the outpatient medical consultations, shower, frequency of use of the terminal points, and temperature. Logistic regression model revealed that outpatient medical consultations $(p=0.058)$, shower $(p=0.007)$ and the frequency of use of the terminal points $(p=0.001)$ are predictors of Legionella colonization.

Conclusions: The inclusion of rapid techniques (IMS, PCR) in the development of a new standard index offer increased sensitivity of Legionella detection improving classical control strategies usually based on the culture method. The proportion of hospital water-system sites testing positive, according to the defined standard index, was well correlated with the frequency of use of terminal points and the temperature, suggesting that the control of these factors may help prevent legionnaires' disease in the hospital.

\section{Background}

Legionellosis is an atypical pneumonia that is acquired when inhaling water drops contaminated with pathogenic bacteria belonging genus Legionella and they reach the lungs and replicate in macrophages (1). Legionellae are ubiquitous water-borne gram-negative bacilli. Legionellosis is primarily associated with two clinically distinct syndromes: Legionnaires' disease (LD), a potentially fatal form of pneumonia, and Pontiac fever, a self-limited, non-pneumonic illness, which usually resolves on its own without hospitalization or antibiotic treatment, within 2-5 days, so that it is generally not diagnosed. LD is the pneumonic form of legionellosis, with a case-fatality rate of $10 \%$ (25\% for healthcare-associated infections). Mortality is higher in admitted patients and immunosuppressed patients, reaching $80 \%$ ever 
with proper treatment $(2,3)$. In developed countries, the incidence has increased largely due to the introduction of clinical diagnostic tests, such as the test for detection of Legionella pneumophila serogroup 1 antigen in urine samples (2).

Legionellosis is a relevant pathology of increasing impact on human health. In 2016, in the 30 countries of the European Union, 6,560 cases were confirmed by the European Legionella Surveillance Network (European Legionnaires' Disease Surveillance Network - ELDSNet) (4). The exact incidence of legionellosis worldwide is difficult to measure and compare because countries have many differences in the methods of definition and notification of cases, having a low notification rate $(2,5,6)$. Legionella is an important cause of both community-acquired and nosocomial pneumonia. The incidence of nosocomial infections is very low (7), but it represents a major public health concern mainly because nosocomial cases occur in a significant proportion in patients without any specific risk factor, and also due to the high lethality (50\% in the Valencian Community, Spain). $(8,9)$

The presence of bacteria in water is considered a prerequisite for infection $(10,11)$. The growth of Legionella depends on several factors, among others, $\mathrm{pH}$ and hardness of the water, presence of old pipes, standing water, difficulty in maintaining the right temperature, biofilm formation, and the pipe length as an indirect factor (12) (13). In particular, health structures, including hospitals, health centers, residences, and dialysis centers, may present a risk environment for the transmission of LD due to the use of an old water network and the commissioning of medical devices with immunocompromised patients $(14,15)$. Most of the sanitary water networks of the hospitals have been colonized by Legionella and, over time, it can cause the appearance of cases of nosocomial legionellosis.

Guidelines and regulations for the primary prevention of legionellosis (ie, Legionnaires' disease and Pontiac fever) have been developed by various public health and other government agencies. These guidelines are similar in recommending maintenance of building water systems; federal and other guidelines differ in the population/institutions targeted, the extent of technical detail, and support of monitoring water systems for levels of Legionella contamination. However, LD outbreaks are not uncommon despite guidelines and regulations are widely known and implemented (16). In Spain, for example, the regulation is focused on the levels of chlorine and temperature as risk factors, which is clearly insufficient. On this last point, the correct management of water quality, by including both cleaning procedures and rapid methods of analyzing Legionella in water, is considered as a critical issue to prevent LD outbreaks $(17,18)$. This is due, among other factors, to the inability to predict the changes of the concentrations of free and intact Legionella in the aqueous phase, from which bioaerosols are generated (19).

All the factors explaining both colonization and infection of Legionella in sanitary environments are not yet clear $(20,21)$. Volker et al. have tried to study some of these factors such as temperature, water stagnation and the pipe length. However, it must be considered that this study was not carried out on a sanitary structure, which involves specific difficulties and characteristics regarding a building for domestic use, so that the factors to be studied may be different. In addition, the author demonstrates that 
traditional culture-based methods are not always able to reveal the risk of Legionella contamination and water infection (13). For this reason, it is very important to study the factors that can be associated with an increase in the presence of Legionella in the water of a sanitary structure. Furthermore, a control of legionella colonization in a healthcare environment can improve health globally. In this context, the aim of this study is to evaluate the frequency of use of terminals points like a risk factor for Legionella colonization in a hospital (22).

\section{Methods}

\section{Data and sample collection}

Water samples were collected from different critical points distributed in the different floors and pavilions at the University Clinical Hospital of Valencia (Spain), according to UNE Standard, in January, May and October 2017.

A volume of five liters of water was collected for each sample and divided in four portions, which were distributed among three laboratories accredited by the norm ISO 17025, as follows: 1 liter-portion for LAB 1, 1 liter-portion for LAB2, and 2 liter-portion for LAB3. The remaining 1 liter-portion was discarded. The temperature of the samples was measured at the time of collection. The samples were transported directly to the different laboratories under controlled temperature of $5 \pm 3^{\circ} \mathrm{C}$ and simultaneously analyzed by all of them. The time between the collection of the samples and the execution of the Legionella assays was less than 24 hours.

Three type of assays were conducted by the laboratories: Legionella culture method on GVPC Agar (Biomerieux, Madrid, Spain), qPCR (IELAB, Alicante, Spain) and immunomagnetic separation (IMS) based method (Legipid® Legionella Fast Detection Test, Biótica, Spain). The samples were analyzed by culture and IMS methods for both LAB 1 and LAB2. The LAB 3 samples were analyzed by culture, IMS and PCR techniques. $L A B 3$ used one liter of sample for conducting both the culture and IMS techniques, as the other laboratories, and used another liter of sample for conducting PCR technique. Each 1 liter-portion for each sample was mixed by shaking it manually and then it was filtered through a $0.4 \mu \mathrm{m}$-pore diameter polycarbonate membrane filter (Millipore). The membrane filter was then removed and placed with $15 \mathrm{ml}$ of the diluent LO (Biótica) in a $100 \mathrm{ml}$ sterile container and then vigorously vortexed for 2 minutes. After that, nine milliliters of this concentrate were assayed by IMS based method (Legipid® Legionella Fast Detection Test, Biótica) and the rest of the volume was used to conduct the culture assay for Legionella species following the norm ISO 11731 (23).

For qPCR trial (LAB3) each 1-liter water sample was mixed by shaking it and filtered through a $0.2 \mu \mathrm{m}$ pore diameter polycarbonate membrane filter (Millipore). The membrane filter was then removed and placed with $10 \mathrm{ml}$ of sterile water and a portion of this concentrated was assayed by qPCR. This kit includes internal controls to control sample inhibitions or non-optimal reactions. 
A new type of standard was used for diagnosis through consensus among three microbiologists from the three laboratories as it is described in the state-of-the-art, considering both culture, PCR and Legipid ${ }^{\circledR}$ Legionella Fast Detection test results (24).

Among the three participating laboratories cited above, a total of 527 water samples were examined to develop the standard index. Of these, $252(47.82 \%)$ were cold water and $275(52.18 \%)$ were hot water. Samples from areas where patients could not be exposed were excluded for the analysis, as in the case of water reservoirs and accumulators in the basement of the hospital. Once the index was defined, 136 water samples assayed by the LAB3 using all the analytical techniques (culture, PCR and IMS) was considered for this study. All the variables were recorded in an Excel spreadsheet.

\section{Variables}

The variables to be studied were the type of water, the pipe length, the chlorine, the temperature, the type of terminal point, the period of the year, the type of health assistance (outpatient or hospital), and the frequency of use of the terminal point. A terminal point was considered as frequent if this point was opened for at least 5 minutes every day.

The temperature factor was divided into three categories $\left(<25^{\circ} \mathrm{C}, 25-50^{\circ} \mathrm{C}\right.$, and $\left.>50^{\circ} \mathrm{C}\right)$, given that Legionella multiply where temperatures are between $20^{\circ} \mathrm{C}$ and $50^{\circ} \mathrm{C}$ and that the effectiveness of maintaining sanitary hot water at a minimum temperature of $55^{\circ} \mathrm{C}$ is significantly better than at $50^{\circ} \mathrm{C}$ for Legionella environmental control $(25,26)$.

\section{Statistical analysis}

Statistical data analysis was performed using the SPSS IBM Statistics V 21.0 software package. Univariate, bivariate and multivariate analysis were conducted. Simple statistical analysis was conducted by estimating the odds ratio (OR), bivariate analysis used the Chi square test and the Fisher's exact test, and the binary logistic regression was applied for conducting multivariate adjustment of the risk factors.

\section{Results}

There was no statistically significant difference between the three laboratories (LAB1, LAB2 and LAB3) and there was also no difference between the IMS based method and the culture method (Table 1) confirming that they are equivalent methods as it is described in the validation of IMS-based method (27).

The Floors and Pipe length (distance from the terminal point) were not statistically significant factors. These variables are interrelated so that Pipe length was considered as adjustment variable provided that it is the most objective summary measure and it is cited in the literature. Although it is likely that there are others interacting factors. 
The risk is associated with an increase in temperature above $25^{\circ} \mathrm{C}$ and with hot water. The variable defined as temperature by ranges, which is best adapted to the theoretical behavior of Legionella growth, was included. The shower proved to be a terminal point of risk $(O R=2.05 ; p<0.05)$. Ambulatory health assistance was found to be a risk factor for colonization by Legionella $(\mathrm{OR}=2.9, \mathrm{p}<0.05)$.

Conversely chlorine $(O R=0.090)$ and frequency of use $(O R=0.155)$ were protective factors $(p<0.05)$ (table 2).

In the logistic regression model the parameters of date, type of health assistance, terminal point, frequency of use, pipe length, temperature range and chlorine were considered. The May date $(\mathrm{OR}=$ $0.454 ; p<0.05)$ and Chlorine $(O R=0.032 ; p<0.05)$ turned out to be a protective factor. The odds-ratio $(O R)$ for infrequent use was 12.187 ( $p<0.05)$. The increased risk is also confirmed for the shower point of sampleOR $=8.587 ; \mathrm{p}<0.05)$. The ambulatory health assistance $(O R=12.248)$ was not, however, statistically significant (Table 3 ).

Usage frequency and temperature were taken into consideration. It was found that the hot water was the one that underwent the most changes. At terminal points of infrequent use (NFU) it had a greater percentage of temperatures less than 50 degrees. There was not any point of NFU showing a temperature higher than $55^{\circ} \mathrm{C}$ (which is present at points of frequent use - FU) (fig 1 ).

\section{Discussion}

Legionellosis was included in 1996 among notifiable diseases at the national level in Spain (Royal Decree 2210/95). In the Community of Valencia, the Basic Surveillance System, including legionellosis as a Notifiable Disease (OED), was developed by the Ordinance of March 4, 1997. Ten years later, in 2017, 236 cases of legionellosis were declared with an incidence rate of 4.7 cases per 100,000 inhabitants (9).

The national regulation currently in force is the Royal Decree 865/2003, which is an old text (28). Currently, this law notes the culture method described in IS01173:1998 for the Legionella assay in water samples from cooling towers, but not explicitly for other risk installations. However, culture method is a slow method that can lead to a delay in taking timely steps on the facilities to prevent risk situations $(23,28,29)$.

Although recovery and isolation of Legionella colonies by culture is recognized as the gold standard method, well-known limitations of this method could compromise their utility in preventative or rapid control action. Among these drawbacks, we can highlight: (a) long time to confirm results (from 2 to 28 days are required), (b) changes on environmental water samples have been identified during their transport to laboratory, which might take up to 1-2 days, (c) likely presence of viable and infective but noculturable cells, (d) poor sensitivity, and (e) a rate of inconclusive results up to $20 \%$ by interfering microbiota $(30,31)$. 
The new standard UNE 100030: 2017 (29) tries to cover the lag of the Royal Decree by incorporating new technical requirements in the prevention and control of Legionella with the main objective of complementing it. One of the main contributions of the new standard is the explicit recognition of alternative not growth-based methods to the culture for the detection of Legionella, if they meet the specified technical requirements on validation and certification.

Nevertheless, although some technical recommendations are established in section 6.15 of this standard, it is not applicable to facilities of sanitary/therapeutic use, so the development of other complementary initiatives can be expected.

Given the importance of fast detecting the presence of Legionella and knowing the factors that determine the quickly facilities colonization by this bacterium, it is necessary to define a new standard of Legionella determination which is not based on culture method, and also to develop new diagnostic methods.

According to the Royal Decree $865 / 2003$, regulation on the prevention and control of legionellosis in Spain, a temperature between $25^{\circ} \mathrm{C}$ and $50^{\circ} \mathrm{C}$ is considered a risk factor for the proliferation and colonization of Legionella. In fact, thermal disinfection (hot water overheating) was the first method used to control Legionella in water distribution systems in hospitals $(32,33)$. Water at $70{ }^{\circ} \mathrm{C}$ kills Legionella pneumophila in 10 minutes, while at $60^{\circ} \mathrm{C}$ it takes 25 minutes (34). The temperature rise above $60{ }^{\circ} \mathrm{C}$ for several days ensures the success and absence of legionellosis (35). Its advantage lies in its minimum cost. However, the loss of heat in some points of the hot water distribution network (heater, recirculation, representative points of use) may cause defective return valves in the faucets, providing generalized temperature losses due to the mixing of cold and hot water. Moreover, although thermal disinfection is the most common, economical and effective treatment for the Legionella control, it does not eliminate the bacterial biofilm, which protects Legionella (36).

In our study, the average temperature is higher in the points of frequent use than those of infrequent use. The importance of maintaining temperatures above $50^{\circ} \mathrm{C}$, and even better above $55^{\circ} \mathrm{C}(26)$, is well known.

Furthermore, more Legionella positive results were found using the new standard index than using a single technique, whether it is culture or IMS, only for temperatures around $40-50{ }^{\circ} \mathrm{C}$ (data not shown). For this reason, it is important to consider not-growth based diagnostic methods, able of measuring Legionella properties other than its growth in an artificial medium on a plate.

The importance of pipe lenght and water stagnation as risk factors for Legionella colonization have also been studied. These studies were conducted in residential facilities (13). The structural complexity of a health facility suggests means that pipe length, floor and pavilion cannot be used as risk factors, while it is important to consider both a correct and frequent use of terminal points (26) to prevent colonization and formation of biofilms. 


\section{Limitations}

A limitation in this work is the difficulty to have a standard for the Legionella assay. The culture method is not a reliable test for the detection of Legionella in water with a preventative value. There is no consensus to establish an environmental diagnostic standard. The criterion used in this study increased the sensitivity of Legionella detection in water. However, it could be necessary to define an internationally validated standard in the future.

\section{Conclusions}

Legionnaires' disease (LD) is recognized as an important hospital-acquired disease. Despite the several methods available, the optimal method to control hospital-acquired LD is not well established and their overall efficacy requires further evaluation. A combination of culture, PCR and IMS techniques offer the best index for detecting Legionella positivity in environmental samples collected at the hospital. This study suggests that this index is effective in detecting Legionella positivity in environmental samples at hospital. Based on this standard index, risk factors have been identified as relevant for the Legionella control in the hospital, mainly the frequency of the use of terminal points.

Differences in Legionella colonization between types of buildings are not due to a variation in water supply but to other factors, such as the specific structural complexity of the water network in a hospital. Besides the importance of pipe length or temperature, this study demonstrated the favorable action of low frequency of use of terminal points on the proliferation and colonization of Legionella. In fact, neighboring terminal points are used with different frequency.

The decrease in the usage frequency of the terminal point causes a temperature lowering in hot water. The frequency of use is related to temperature, the presence of Legionella and probably biofilm. In this sense, the frequency of use, representing a combination of other variables, could be a relevant factor for the control of Legionella in a health establishment.

\section{List Of Abbreviations}
LD: Legionnaires' disease

PCR: polymerase chain reaction

IMS: inmunomagnetic separation

NFU: infrequent use

FU: frequent use

\section{Declarations}




\section{Ethics approval and consent to participate}

This manuscript was approved by the Hospital Clínico Universitario de Valencia (Spain).

\section{Availability of data and material}

Data are available from the authors upon reasonable request and with permission from the Hospital Clínico Universitario de Valencia.

\section{Consent for publication}

Not applicable

\section{Competing interests}

The authors declare that they have no competing interests.

\section{Funding}

No sources of funding required.

\section{Authors' contributions}

Dr. Rafael Ortí is the principal investigator of the Public Health and Patient Safety Research Group at the Catholic University of Valencia. He directed the meetings and the preparation of this document. Eugenio Luciano is the Co-I of this working group. Both authors contributed to the writing of the text. All authors read and approved the final manuscript.

\section{Acknowledgements}

The authors would like to thank the staff of the following laboratories for their help in offering us the resources in running the water assays: Anticimex (LAB1), Ambientalys (LAB2), and Iproma (LAB3).

\section{Reference}

1. Alleron L, Khemiri A, Koubar M, Lacombe C, Coquet L, Cosette $P$, et al. VBNC Legionella pneumophila cells are still able to produce virulence proteins. Water Res [Internet]. 2013;47(17):6606-17. Available from: https://www.ncbi.nIm.nih.gov/pubmed/24064547 
2. Burillo A, Pedro-Botet ML, Bouza E. Microbiology and Epidemiology of Legionnaire's Disease. Infect Dis Clin North Am [Internet]. 2017;31(1):7-27. Available from:

https://www.ncbi.nlm.nih.gov/pubmed/28159177

3. Hashmi HRT, Saladi L, Petersen F, Khaja M, Diaz-Fuentes G. Legionnaires' Disease:

Clinicoradiological Comparison of Sporadic Versus Outbreak Cases. Clin Med Insights Circ Respir Pulm Med. 2017;

4. European Centre for Disease Prevention and Control. Legionnaires' disease. In: ECDC. Annual epidemiological report for 2016. Stockholm: ECDC; 2018. [Internet]. 2016. Available from: https://ecdc.europa.eu/sites/portal/files/documents/legionnaires-disease-annual-epidemiologicalreport.pdf

5. Cassell K, Gacek P, Rabatsky-Ehr T, Petit S, Cartter M, Weinberger DM. Estimating the True Burden of Legionnaires' Disease. Am J Epidemiol [Internet]. 2019 Jun 21 [cited 2019 Jun 26]; Available from: https://academic.oup.com/aje/advance-article/doi/10.1093/aje/kwz142/5521619

6. Organization WH. Legionella and the Prevention of Legionellosis. World Health Organization, Geneva, Switzerland. 2007;

7. SEMPSPH. ESTUDIO EPINE-EPPS 2017. Estudio de Prevalencia de las Infecciones Nosocomiales en España (EPINE) [Internet]. 2017. Available from: http://hws.vhebron.net/epine/

8. Sikora A, Gładysz I, Kozioł-Montewka M, Wójtowicz-Bobin M, Stańczak T, Matuszewska R, et al. Assessment of antibiotic susceptibility of \&lt;i\&gt;Legionella pneumophila\&lt;/i\&gt; isolated from water systems in Poland. Ann Agric Environ Med [Internet]. 2017 Mar 21 [cited 2019 Jun 26];24(1):66-9. Available from: http://www.journalssystem.com/aaem/Assessment-of-antibioticsusceptibility-of-Legionella-pneumophila-isolated-from-water-systems-in-Poland,72609,0,2.html

9. Servicio de Vigilancia y Control Epidemiológico. Sudirección General de Epidemiología V de la S y SA. Informes Legionelosis Comunitat Valenciana del año 2017. Pública C de SU i SPDG de S, editor. 2017.

10. Phin N, Parry-Ford F, Harrison T, Stagg HR, Zhang N, Kumar K, et al. Epidemiology and clinical management of Legionnaires' disease. Lancet Infect Dis [Internet]. 2014 Oct 1 [cited 2019 Mar 8];14(10):1011-21. Available from: https://www.sciencedirect.com/science/article/pii/S1473309914707133?via\%3Dihub

11. Soda EA, Barskey AE, Shah PP, Schrag S, Whitney CG, Arduino MJ, et al. Vital Signs: Health CareAssociated Legionnaires' Disease Surveillance Data From 20 States and a Large Metropolitan AreaUnited States, 2015. [Internet]. Vol. 17(8), Am J Transplant. 2017. p. 2215-20. Available from: https://www.ncbi.nlm.nih.gov/pubmed/28724206

12. Rafiee M, Mesdaghinia A, Hajjaran H, Hajaghazadeh M, Miahipour A, Jahangiri-Rad M. The Efficacy of Residual Chlorine Content on the Control of Legionella Spp. In Hospital Water Systems [Internet]. Vol. 43, Iranian J Publ Health. 2014 [cited 2019 Jun 26]. Available from: http://ijph.tums.ac.ir

13. Völker S, Schreiber C, Kistemann T. Modelling characteristics to predict Legionella contamination risk - Surveillance of drinking water plumbing systems and identification of risk areas. Int J Hyg Environ 
Health [Internet]. 2016 Jan;219(1):101-9. Available from:

https://linkinghub.elsevier.com/retrieve/pii/S1438463915001248

14. Cristina ML, Spagnolo AM, Sartini M, Dallera M, Ottria G, Perdelli F, et al. Investigation of organizational and hygiene features in dentistry: a pilot study. J Prev Med Hyg [Internet]. 2009;50(3):175-80. Available from: https://www.ncbi.nlm.nih.gov/pubmed/20411652

15. Montagna MT, De Giglio O, Cristina ML, Napoli C, Pacifico C, Agodi A, et al. Evaluation of Legionella air contamination in healthcare facilities by different sampling methods: An Italian multicenter study. Int J Environ Res Public Health. 2017;

16. Man Lai K, Emberlin J, Colbeck I. Environmental Health Outdoor environments and human pathogens in air. 2009 [cited 2019 Jun 29]; Available from: http://www.biomedcentral.com/content/pdf/1476069X-8-s1-info.pdf

17. De Giglio O, Napoli C, Lovero G, Diella G, Rutigliano S, Caggiano G, et al. Antibiotic susceptibility of Legionella pneumophila strains isolated from hospital water systems in Southern Italy. Environ Res. 2015;

18. Fontana S, Scaturro M, Rota MC, Caporali MG, Ricci ML. Molecular typing of Legionella pneumophila serogroup 1 clinical strains isolated in Italy. Int J Med Microbiol [Internet]. 2014;304(5-6):597-602. Available from: http://dx.doi.org/10.1016/j.ijmm.2014.04.004

19. Bentham R, Whiley H, Bentham R, Whiley H. Quantitative Microbial Risk Assessment and Opportunist Waterborne Infections-Are There Too Many Gaps to Fill? Int J Environ Res Public Health [Internet]. 2018 Jun 1 [cited 2019 Jun 26];15(6):1150. Available from: http://www.mdpi.com/1660$4601 / 15 / 6 / 1150$

20. Nishida T, Hara N, Watanabe K, Shimizu T, Fujishima M, Watarai M. Crucial Role of Legionella pneumophila TolC in the Inhibition of Cellular Trafficking in the Protistan Host Paramecium tetraurelia. Front Microbiol [Internet]. 2018 Apr 25 [cited 2019 Jun 26];9:800. Available from: http://journal.frontiersin.org/article/10.3389/fmicb.2018.00800/full

21. Dietersdorfer E, Kirschner A, Schrammel B, Ohradanova-Repic A, Stockinger H, Sommer R, et al. Starved viable but non-culturable (VBNC) Legionella strains can infect and replicate in amoebae and human macrophages. Water Res [Internet]. 2018 Sep [cited 2019 Jun 26];141:428-38. Available from: https://linkinghub.elsevier.com/retrieve/pii/S0043135418300721

22. Hamilton KA, Hamilton MT, Johnson W, Jjemba P, Bukhari Z, Lechevallier M, et al. Risk-Based Critical Concentrations of Legionella pneumophila for Indoor Residential Water Uses. 2019 [cited 2019 Jun 26]; Available from: https://pubs.acs.org/doi/10.1021/acs.est.8b03000.

23. ISO 11731:2017 - Water quality-Enumeration of Legionella [Internet]. 2017 [cited 2019 Jun 26]. Available from: https://www.iso.org/standard/61782.html

24. Luciano E, Bediaga Collado A, Saa Casa A, Solis Andrés I, Ortega Llavador B, Ortí Lucas RM. Comparación de método rápido de detección de Legionella (SIM) y cultivo con estándar en agua caliente sanitaria y agua fría en un centro sanitario. Rev Salud Ambient. 2019;19:211. 
25. Proctor CR, Dai D, Edwards MA, Pruden A. Interactive effects of temperature, organic carbon, and pipe material on microbiota composition and Legionella pneumophila in hot water plumbing systems. [cited 2019 Jun 29]; Available from: https://www.ncbi.nlm.nih.gov/pmc/articles/PMC5628487/pdf/40168_2017_Article_348.pdf

26. Gavaldà L, Garcia-Nuñez M, Quero S, Gutierrez-Milla C, Sabrià M. Role of hot water temperature and water system use on Legionella control in a tertiary hospital: An 8-year longitudinal study. Water Res. 2019 Feb 1;460-6.

27. Albalat GR, Broch BB, Bono MJ. Method Modification of the Legipid $\circledR^{\circledR}$ Legionella Fast Detection Test Kit. J AOAC Int [Internet]. 2014 Sep 1 [cited 2019 Jun 29];97(5):1403-9. Available from: http://www.ncbi.nlm.nih.gov/pubmed/25902991

28. Real Decreto $865 / 2003$, de 4 de julio, por el que se establecen los Criterios Higiénico-Sanitarios para la Prevención y Control de la Legionelosis. BOE núm. 171, de 18 de julio. 2003.

29. Norma UNE 100030. Prevención y control de la proliferación y diseminación de Legionella en instalaciones. 2017.

30. Lee TC, Vickers RM, Yu VL, Wagener2 MM. Growth of 28 Legionella Species on Selective Culture Media: a Comparative Study [Internet]. Vol. 31, JOURNAL OF CLINICAL MICROBIOLOGY. 1993 [cited 2019 Jun 26]. Available from:

https://www.ncbi.nlm.nih.gov/pmc/articles/PMC266009/pdf/jcm00022-0226.pdf

31. García MT, Jones S, Pelaz C, Millar RD, Abu Kwaik Y. Acanthamoeba polyphaga resuscitates viable non-culturable Legionella pneumophila after disinfection. Environ Microbiol [Internet]. 2007 May 1 [cited 2019 Jun 26];9(5):1267-77. Available from: http://doi.wiley.com/10.1111/j.14622920.2007.01245.x

32. Best M, Yu VL, Stout J, Goetz A, Muder RR, Taylor F. Legionellaceae in the hospital water-supply. Epidemiological link with disease and evaluation of a method for control of nosocomial legionnaires' disease and Pittsburgh pneumonia. Lancet (London, England) [Internet]. 1983 Aug 6 [cited 2019 Jun 27];2(8345):307-10. Available from: http://www.ncbi.nlm.nih.gov/pubmed/6135832

33. Lin YS, Stout JE, Yu VL, Vidic RD. Disinfection of water distribution systems for Legionella. Semin Respir Infect [Internet]. 1998 Jun [cited 2019 Jun 27];13(2):147-59. Available from: http://www.ncbi.nlm.nih.gov/pubmed/9643393

34. Stout JE, Lin YS, Goetz AM, Muder RR. Controlling Legionella in hospital water systems: experience with the superheat-and-flush method and copper-silver ionization. Infect Control Hosp Epidemiol [Internet]. 1998 Dec [cited 2019 Jun 27];19(12):911-4. Available from: http://www.ncbi.nlm.nih.gov/pubmed/9872527

35. Best M, Goetz A, Yu VL. Heat eradication measures for control of nosocomial Legionnaires' disease. Implementation, education, and cost analysis. Am J Infect Control [Internet]. 1984 Feb [cited 2019 Jun 27];12(1):26-30. Available from: http://www.ncbi.nlm.nih.gov/pubmed/6422800

36. Sikora A, Kozioł-Montewka M, Wójtowicz-Bobin M, Gładysz I, Dobosz P. [The hazards of hospitals and selected public buildings of Legionella pneumophila]. Pol Merkur Lekarski [Internet]. 2013 Nov 
[cited 2019 Jun 27];35(209):263-7. Available from: http://www.ncbi.nlm.nih.gov/pubmed/24575645

\section{Tables}

Table 1. Difference between laboratories and methods

\begin{tabular}{cccccc}
\hline & n (\%) & OR & $95 \%$ CI & $p$ \\
\hline Laboratory & & & & & \\
\hline LAB 1 & $56(19)$ & 1 & & & \\
\hline LAB 2 & $102(34,7)$ & 1,442 & 0,748 & 2,781 & 0,274 \\
\hline LAB 3 & $136(46,3)$ & 1,414 & 0,755 & 2,647 & 0,279 \\
\hline Method & & & & & \\
\hline Culture & $164(55,8)$ & 1 & & & \\
\hline IMS & $130(44,2)$ & 1,000 & 0,631 & 1,585 & 1 \\
\hline
\end{tabular}

Table 2. Bivariant analysis of different factors 


\begin{tabular}{cccccccc} 
& $\mathrm{n}(\%)$ & $\mathrm{OR}$ & & $95 \% \mathrm{CI}$ & & $p$ \\
\hline Date & & & & & & \\
\cline { 1 - 3 } Gen & $26(19,1)$ & 1 & & & \\
May & $56(41,2)$ & 0,643 & 0,252 & 1,638 & 0,354 \\
Oct & $54(39,7)$ & 1,247 & 0,486 & 3,201 & 0,647 \\
\hline
\end{tabular}

Type of assistance

$\begin{array}{lccccc}\text { Hospital } & 108(74,9) & 1,000 & & & \\ \text { Ambulatory } & 28(20,6) & 2,900 & 1,176 & 7,154 & 0,021\end{array}$

Floors

\begin{tabular}{cccccc}
1 & $6(4,4)$ & 1 & & & \\
2 & $20(14,7)$ & 0,750 & 0,110 & 5,109 & 0,769 \\
3 & $16(11,8)$ & 0,833 & 0,115 & 6,013 & 0,857 \\
4 & $26(19,1)$ & 0,800 & 0,123 & 5,202 & 0,815 \\
\hline 5 & $30(22,1)$ & 0,438 & 0,069 & 2,762 & 0,379 \\
\hline 6 & $10(7,4)$ & 0,333 & 0,040 & 2,769 & 0,309 \\
\hline 7 & $20(14,7)$ & 0,214 & 0,031 & 1,504 & 0,121 \\
\hline 8 & $8(5,9)$ & 0,500 & 0,056 & 4,473 & 0,535 \\
\hline
\end{tabular}

Point of sample

$\begin{array}{llclll}\text { washbasin } & 54(39,7) & 1 & & & \\ \text { shower } & 82(60,3) & 2,053 & 1,021 & 4,128 & 0,043\end{array}$

Frecuency of Use

$\begin{array}{llclll}\text { not frequent } & 41(30,1) & 1 & & & \\ \text { frequent } & 95(69,9) & 0,155 & 0,064 & 0,371 & 0,000\end{array}$

Type of water

Hot water $68(50) \quad 1$

$\begin{array}{llllll}\text { Cold water } & 68(50) & 0,111 & 0,051 & 0,241 & 0,000\end{array}$

\section{Temperature Range $\left({ }^{\circ} \mathrm{C}\right)$}

$\begin{array}{lccccc}<25 & 56(41,2) & 1 & & & \\ 25-50 & 48(35,3) & 3,500 & 1,548 & 7,913 & 0,003 \\ >50 & 32(23,5) & 10,833 & 3,752 & 31,277 & 0,000\end{array}$

Pipe lenght (m)

$\begin{array}{llll}0,997 & 0,986 & 1,008 & 0,562\end{array}$ 
Table 3. Logistic regression considering all important factors

\begin{tabular}{|c|c|c|c|c|}
\hline & OR & & $\% \mathrm{CI}$ & $p$ \\
\hline \multicolumn{5}{|l|}{ Date } \\
\hline Gen & 1 & & & \\
\hline May & 0,150 & 0,028 & 0,808 & 0,027 \\
\hline Oct & 0,454 & 0,092 & 2,238 & 0,332 \\
\hline
\end{tabular}

Type of health assistance

Hospital 1

Ambulatory $\begin{array}{llll}12,248 & 0,923 & 162,533 & 0,058\end{array}$

Point of sample

washbasin

1

Shower

$8,587 \quad 1,781 \quad 41,387 \quad 0,007$

Frequency of Use

Frequent

1

Unfrequent

$\begin{array}{llll}12,187 & 2,650 & 56,044 & 0,001\end{array}$

Pipe lenght (m)

$\begin{array}{llll}1,006 & 0,986 & 1,027 & 0,555\end{array}$

Temperature Range

$<25$

1

25-50

$\begin{array}{llll}0,483 & 0,105 & 2,220 & 0,350\end{array}$

$>50$

$\begin{array}{llll}0,626 & 0,087 & 4,522 & 0,642\end{array}$

Chlorine (mg/l)

$\begin{array}{llll}0,032 & 0,005 & 0,203 & 0,0003\end{array}$

\section{Figures}




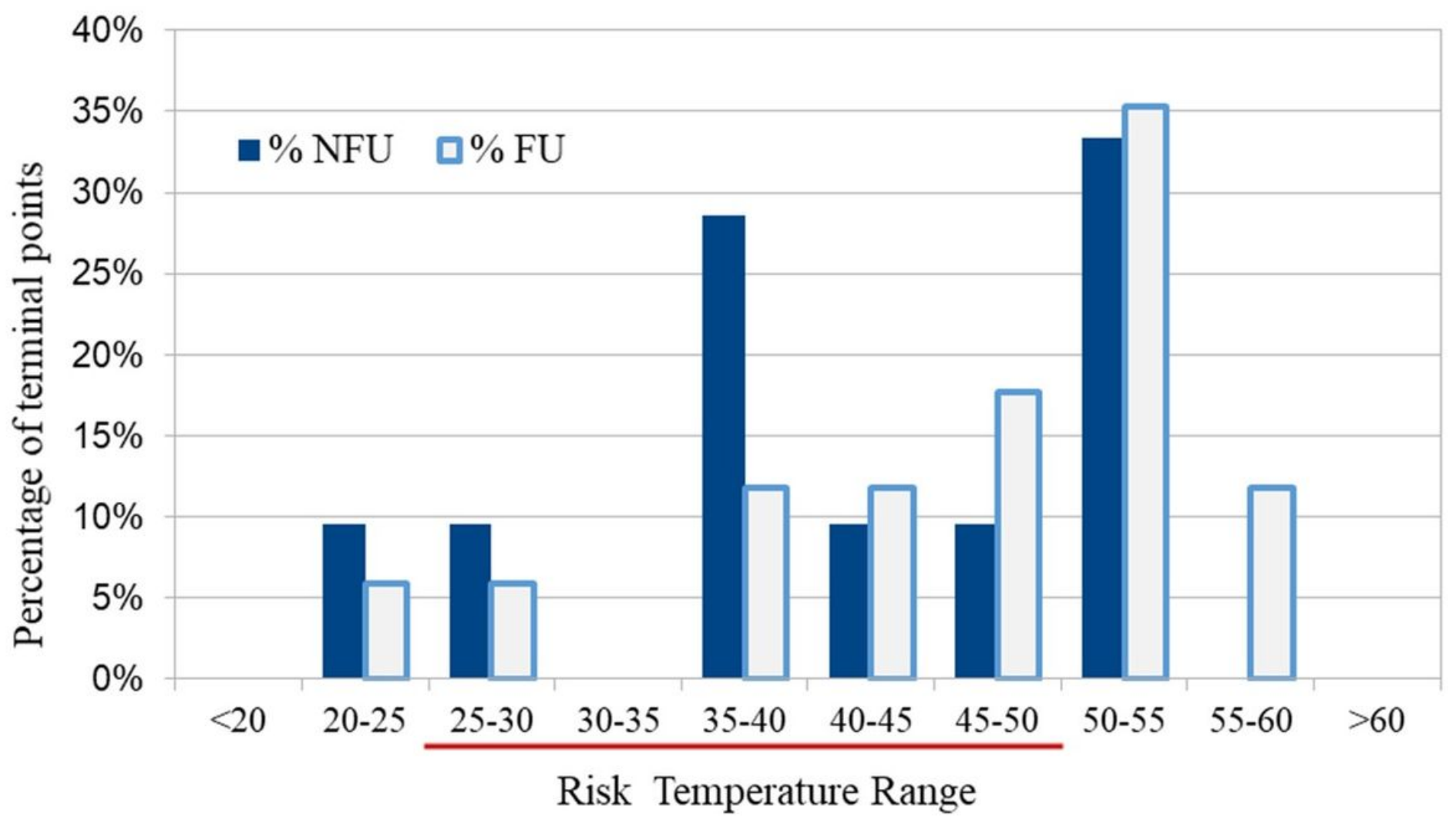

Figure 1

Percentage of terminal points with a given temperature range (differently colored). Comparison between points of infrequent use (NFU) and points of frequent use (FU). 